\title{
Rethinking Pedagogy in Multiple Educational Contexts: A Glocal Framework to ICT Meaningful Approaches to Learning
}

\author{
A. Paulino, A. Mouta, J. Ferreira, N. Andrade, H. Quintela \\ JP-inspiring knowledge, Portugal
}

\begin{abstract}
The rapid dissemination of ICT in the postcontemporary world is raising new challenges, namely in terms of information, knowledge and learning. An education policies movement is trying to formally address the challenges posed by educational projects that intentionally include ICT in formal learning spaces, from the design of those initiatives to the evaluation phases. In this context, a comprehensive integrative methodology seems critical to create adequate implementations and prompt meaningful results from ICT usage as a learning medium. The $i k$-Model presented in this article is a JP-ik framework - forged from field experience and validated in real case scenarios around the world (Europe, Africa, Middle East and Latin America) - that aims to guide and support a meaningful integration of new technologies in singular education scenarios, engaging stakeholders across the whole spectrum of the process. This model proved to be effective as a glocal approach that contextually addresses each component of an ICT integrative project for education, fulfilling the potential of ICT in terms of the enhancement of real and meaningful (learning and living) opportunities for all.
\end{abstract}

\section{Introduction}

The contemporary digital divide has been a preoccupation of educational decision makers when thinking on the demands and challenges of the Public School. An initial idea of creating more schools or delivering more technology seemed adequate to face the social digital divide, but the perspective of a second divide is now calling attention to the quality of the education being delivered and to its effects in terms of citizenship and social and economic development. Even the Human Capital Theory is now considering the implications of education quality in terms of (social) return on investment. A reformulation of the Human Capital Theory has stressed the significance of education and training as the key to participate in the new global economies [1].
Based on the assumption that the integration of new technologies in schools assures greater equal conditions for learners to learn and learning to happen and that it may foster better strategic life choices, literacy levels, agency and functioning, the technological modernization of schools is systematically being pointed out in many political and academic educational debates [2]. Usually, the educational ICT projects that are established after some consensus on these debates are based on strategic policies that promote ICT use: $i$ ) to support economic growth, through a better prepared workforce that uses new technologies as productivity tools and applies generative skills to foster knowledge creation, innovation and entrepreneurship; ii) to promote social development, raising extended access to education, as well as enhancing social cohesion and sociocultural participation; and iii) to advance pedagogical reform, introducing ICT along with pedagogical innovation or curriculum restructuring (development of $21^{\text {st }}$ century skills and reinforcement of one's ability to direct her/his own learning and to apply concepts to solve complex real-world problems) [3][4].

Whatever the focus may be, a systemic education change that challenges pedagogical methodologies is needed to accomplish these goals. ICT is the argument that creates the opportunity to rethink Pedagogy and Education horizons. Any attempt to change is expected to take into account the specificity of the context, the project baseline and the way it is addressing the needs of the different educational players involved. Several theoretical approaches have been focusing on the categories that can be generated by the needs of a major educational change and some frameworks are being used as guidelines to design, implement, monitoring and assess ICT educational projects.

UNESCO frameworks for ICT integration in educational systems offer a macrosystemic approach that has improvement as a focal point. UNESCO Knowledge Ladder proposal considers four progressive stages of education change - (1) Basic Education, (2) Knowledge Acquisition, (3) Knowledge Deepening, 
and (4) Knowledge Creation - that may support the initial evaluation of the education system, help to structure adequate and achievable transformation goals, and guide a meaningful teacher training approach [3]. The first stage is focused on using ICT to improve teachers' subject knowledge and pedagogic skills, in order to create better opportunities for the students to develop literacy and numeracy skills. The second stage is oriented to reinforce students' technological and digital skills, adding ICT as a separate subject or a tool that is punctually used to improve students' deeper understanding of subjects and their ability to apply content knowledge in real-world situations. The third stage considers the use of ICT as an effective learning tool and the integration of digital literacy skills with the curriculum, through curricular infusion strategies and interdisciplinary approaches. And finally, in the fourth stage, an integration of curricular knowledge with $21^{\text {st }}$ century and lifelong learning skills is valued, using ICT to enhance the development of these skills and having teachers as "master learners who model the learning process for their students" [3, p.26]. These stages are related to the ones UNESCO proposes on their ICT adoption framework - (1) Emerging, (2) Applying, (3) Infusing, and (4) Transforming - that can be mapped for teaching and learning using ICT [5]. At the Emerging stage there is an awareness and a rudimentary use of ICT, without any pedagogical change, while at the Applying stage, there is a focus on understanding how to use ICT in subject learning to enhance traditional practices. Then, at the Infusing stage the main focus is media literacy acting as a learning facilitator, and the Transforming stage describes a specialized use of ICT in order to create and manage innovative and open learning environments.

Another approach concerning ICT adoption in formal learning scenarios is the SAMR Model (Substitution, Augmentation, Modification and Redefinition), proposed by Puentedura [6]. The two initial stages consider a progressive enhancement of learning processes using ICT as educational tools, while the two final stages are related to a higher progressive transformation of learning scenarios, redesigning and creating new learning activities through ICT contextual integration.

In the conceptual field it is also important to mention the TPACK (Technological, Pedagogical and Content Knowledge) framework, proposed by Mishra and Kohler [7], as a main guideline in terms of teachers' knowledge on educational technology integration. It highlights the three knowledge domains - and the specificity of its multiple combinations - as well as teachers' expertise regarding each combinational domain, while designing, implementing and assessing educational ICT projects.

\section{The ik-Model framework}

The ik-Model was developed under a qualitative analysis that had some main questions as guiding principles. Having the previously mentioned frameworks in mind, a key question that has been raised was: can Pedagogy be addressed as one of those knowledge domains presented on the TPACK? If we understand that any decision made in terms of education and its resources must be a pedagogical one, pedagogy cannot be a part of the process: it must be the Process. Based on this assumption, any decision regarding content, (technological) resources, learning outcomes, and people involved must be pedagogically driven. Another question that was in the origin of the qualitative survey done had to do with context: how is Context placed in the existing approaches and how should it be addressed? Finally, this survey also intended to understand how can people (and their particular relations) be engaged in these educational proposals?

Bearing all these questions in mind, the ik-Model depicted in Figure 1 is presented as a JP-ik proposal, created and developed with different educational players, in the context of a Portuguese national project that aimed to develop Pedagogy within a strategy for ICT meaningful integration in learning scenarios [2]. This framework was created in context, throughout a school-year of nine months, close to different educational players: one ERTE-MoE (Ministry of Education Team for Educational Technologies and Resources) Coordinator, seven DRE'S-MoE (Regional Direction for Education from the Ministry of Education) stakeholders, eight municipality stakeholders, six school cluster principals, one principal assistant, twenty nine primary teachers, thirty seven parents and seventy six students. After a phase of data collection on representations, attitudes and levels of ICT integration [8], six pedagogical consultants were placed in six schools throughout a school trimester, in different regions of Portugal. The aim of this work was the development of a strategy for ICT meaningful integration with teachers, school coordinators, students and parents in their own learning communities. Each activity was designed in terms of a meaningful exploration of the curriculum in a more differentiated manner; its dynamics and effects were thought within a community of "best integrative practices". For all the teachers comprised in this qualitative project, innovative pedagogical practices were a natural effect of using new technologies on their classrooms, where knowledge was at the centre of the negotiation between technologies and practices and meaning at the heart of the contextual learning design [2]. All learning agents were therefore seen as part of a knowledge continuum, where both students and 
teachers were expected to be "emancipated spectators" - using Rancière's concept of spectatorship [9]. As a result of the work developed within these different classroom contexts and educational communities we came across some invariants that were conceived in each transformative learning approach with ICT. The ik-Model is the graphic representation of those conceptual dimensions.

This model functions as a reference guide to different stages of the technological integration process in educational scenarios and it is differently operationalized at each one: (1) project design, development and implementation, at a macro level or considering a specific learning environment; (2) different stakeholders training and high quality professional development; and (3) project monitoring and evaluation, revealing its capacity to produce specific gains and enabling to recognize the particular conditions in which they are produced.

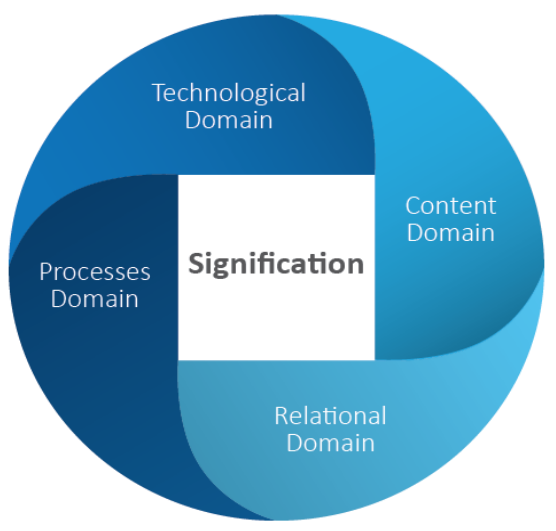

Figure 1. The ik-Model: a framework for ICT meaningful integration in learning scenarios

This proposal considers the technological domain as one of five parts when we think about meaningful ICT integration. The Technological Domain includes the resources and technological tools that can be used to achieve specific goals, what obviously has to do with media literacy - the capacity to choose the most accurate medium to fulfil a specific interest. This is a pedagogical challenge that different educational agents have to answer in order to accomplish meaning through particular strategies and processes. This immediately shows that each one of these parts are elliptical and that they take into account all the others. The Content Domain includes the educational challenges that are transformed into learning goals, knowledge and skills and that are expected to be addressed in formal educational scenarios. The curricular infusion of larger developmental goals and meaningful everyday information beyond curriculum is intentionally considered as the main pedagogical strategy when actively including ICT in formal education. These domains enable stakeholders and pedagogues to select the type of content and resources that accurately fit the learning aims, always remembering the people involved and their real capabilities, as well as the perspectives and roles they assume within the process. The Relational Domain considers all the community in which the project will take place and the way some attitudes - that can facilitate or compromise a deep and shared engagement - are spread. Through this approach we may understand processes of resistance or commitment from within, helping developing a significant leadership to the projects' rollout. In fact, the Processes Domain crosses all the mentioned components, comprising the strategies and the methodologies that are used in order to achieve specific goals, while reinforcing engagement. Only the intersection between these dimensions and the extent to which each one is intentionally revised in all the others enables us to put Signification at the heart of any developmental approach. When signification is considered we are not acting outside the collective capacity to participate in the meaning event, neither are we using a previous heuristic for learning. The expectations can go beyond particular outcomes and communities can engage with other views, opportunities and significant elements.

\section{Glocal approaches using the ik-Model}

The ik-Model has been used by JP-ik in several educational ICT implementation projects around the world and it proves to be a comprehensive approach that helps to capture and address the singularity of different learning scenarios. It supports the continuous identification, integration and evaluation of goals, knowledge, means, strategies and stakeholders involved. Some evidences from JP-ik projects implemented in Europe, Africa, Middle East and Latin America will be shared to support this glocal perspective.

\subsection{Portugal - A Governmental Initiative and the importance of a Meaningful Methodology}

Since 2008, the Portuguese Government has invested in a national project to modernize different public services and infrastructures. In the Education sector, schools were provided with internet access, computers and interactive whiteboards. Also special conditions were provided for both teachers and students to purchase a personal laptop. e-Escolinha was specifically designed to offer Primary students' families affordable conditions to acquire a first 
personal computer with educational content. It had two main goals: to generalize the use of computer and internet since the first years of learning and to assure the access to the first computer by thousands of families. In fact, to extend students' and families' access to new technologies was an important goal that was accomplished with this initiative and then widely recognised. However, after four years of rollout, schools were not becoming the learning spaces that were once conceived in terms of ICT integration, especially regarding the implementation of one-to-one learning approaches.

A comprehensive data analysis which intended to screen ICT integration in different Portuguese schools all over the country, collecting discourses on this topic from stakeholders to school communities, has shown a gap between the types of ICT use and the significance of uses in schools and homes. This study made it clear that the problem was not a technological one. Using the ik-Model in this analysis, it is possible to note that in terms of the technological domain there was just a short period of training mainly oriented to develop or reinforce teachers' technological skills. In what concerns the content domain, Portugal had two main digital educational content Publishers that offered different views of the pedagogical strategies to include ICT in schools. Considering the relational domain, the study has demonstrated that there was no project's meaning amongst the central players within schools, revealing the effects of a pure top-down decision approach to the project design. In terms of the processes domain there were random approaches to integration, from traditional uses of the available devices to blended learning. Working close to school directors, teachers, parents and students it was possible to highlight the importance of aligning the use of technological resources to different learning goals (curricular and generative), through curricular infusion strategies and interdisciplinary approaches, in order to achieve knowledge deepening and knowledge creation (that teachers and schools are looking for).

Nowadays, Portuguese ICT panorama has three main characteristics: grosso modo, (i) schools and homes are technologically well equipped; (ii) teachers use ICT for their work preparation and they also use them within classrooms without great transformation of traditional classes and (iii) a (digital) literacy gap remains between generations and also between welleducated and less well-educated citizens. Pedagogical strategical and meaningful innovation is therefore a requirement and should be the focal point of teacher training in these kinds of project. This is already reinforcing the emergence of new Portuguese pedagogical projects that meaningfully integrate ICT, exploring one-to-one strategies, flipped classroom, robotics, and so on.

\subsection{Angola - Improving Learning Opportunities for all}

In Angola new technologies integration in education is at an early stage. To extend the access to education and to improve its quality - through curricular reform and teacher training - are the more pressing issues. The Government and publishers from the National Institute of Education Research and Development (INIDE) are involved in the project "meu KAMBA" design and implementation. A group of 600 teachers is being engaged in the project and some of them will become master trainers of their peers in this huge educational ICT implementation in Angola primary schools. This implementation aims at the development of several educational plans through online and offline content and it intends to reach a large group of the Angolan population.

Therefore all the ik-Model components need to be addressed from the beginning. The technologies considered in the technological domain need to be integrated with all the learning technologies that are already available in the context. The need to explore available and new resources from different sources was reported, but the digitalization of the school books was the first step of this initiative. The content domain is a really important one in this case, as it pertains to curricular reform and the definition of new learning goals, regarding an improvement of content knowledge and an alignment with the Sustainable Development Goals. Topics related to health, youth pregnancy, environment and gender equality are critical to the Angolan people, and education must effectively create opportunities to deal with them, addressing community needs in a better way. This obviously requires changes in the processes domain involving teachers in different pedagogical practices, concerning curricular infusion of generative competencies and interdisciplinary strategies. The relational domain is not an axis being explicitly addressed at this stage of "meu KAMBA", but it is a matter that will be intentionally considered in the training implementation: teacher training needs to address pedagogy in terms of subject knowledge, as well as large technological and media literacy skills concerning the school larger community, in order to reinforce basic education and knowledge acquisition assumptions.

\subsection{Jordan - Educational Innovation}

In Jordan, the Jordan Education Initiative (JEI) has a particularly influential role in the improvement of learning environments, through the integration of several educational technologies and the enhancement of innovative pedagogical practices. JEI works with 
teachers and school directors, as well as with technological solutions' providers for education. New technologies integration seems not to be a huge challenge in local learning scenarios, as many initiatives in schools already cover a wide range of ICT (e.g., interactive whiteboards and scientific calculators). In what concerns the technological domain, the challenge now is to have ICT manipulated by women. Signification also appears as a central axis in those projects - they are designed with a clear alignment with learning goals and community empowerment perspectives, and they address the different ik-Model components.

Even though school enrolment and community empowerment - considering the relational domain are still important issues that the educational system needs to respond to, the current challenge is essentially related to the content and processes domains. There is a clear focus on innovating learning environments, through the integration of new technologies and the design and implementation of different learning practices that reinforce knowledge deepening and knowledge creation opportunities. Related to the processes domain, one-to-one and project-based learning approaches are valued as opportunities to develop students' autonomy, collaboration, critical thinking and vocational development. There is also an important effort in what refers to monitoring and assessment: the aim is to identify meaningful practices and outcomes that could be followed or contextually adjusted along the way. Finally, the content domain is being particularly considered in terms of sciences and attitude change. There's a great effort to bring girls into Sciences, avoiding ideas such as those that accept that there are "gender occupations".

\subsection{Bolivia - Community Empowerment}

The Bolivian case is particularly interesting as a good example of an ICT integrative project that considers new technologies as contextual tools to achieve meaningful education goals. In the Article 4 of The Bolivian Education law, it is stated that one of the Education goals is to "strengthen the development of the intraculturality, interculturality and multilingualism in education and the full realization of Bolivians, for a society of Living Well" [10]. The consolidation and strengthening of a cultural identity of nations and native indigenous people, from science, technology, arts and technology, in complementarity with universal knowledge is one fundamental aim. Even though the Bolivian Government set up the project with an intention of innovating learning ecosystems and extending access to new technologies, their focus is clearly on using them to support Bolivian multilingual, intercultural and intracultural education, supported by the "Socio-Community Productive Educational Model" (MESCP). It was clear that introducing new technological devices created a great opportunity to fully rethink Pedagogy and that it also enabled to experiment, consolidate and integrate the main premises of the MESCP. In this context, the relational axis plays a really important role as it concerns the interactions between different community agents, reinforcing the importance of collaboration and communication, preserving the language cultural heritage. This has also impact in the processes and content domains where personalized learning is not an option, and the skills connected with the curriculum are seen as important as more generative competencies, with a focus on those that reinforce cultural shared identity. These assumptions are clearly aligned with the country's current Plurinational reality and needs, what makes signification an intentional axis of this particular project. In Bolivia, teacher training was designed to ensure an opportunity to create meaningful learning activities that use several technologies to address particular learning goals and reinforce the sense of community participation and cultural links.

\section{Conclusion}

The singularity of each project presented here makes it clear that a one-size-fits-all approach may not be conceived in Education. It is critical to have a comprehensive framework that contextually supports the design, implementation, and evaluation of pedagogical methodologies that integrate new media, if we intend to make learning an experience of meaning. In all the described projects, the ik-Model comprehensive approach proved to be a positive frame comprising some critical aspects of these implementations: the development of the project's identity, the definition of clear and achievable goals, the compromise and engagement of key project stakeholders and implementers, the achievement of meaningful teacher and student outcomes in terms of lifelong development, and, as result of all this, a continuity of the investment on meaningful projects in Education. This way Education will fully respond to our anthropological challenges, positioning itself in its own historical time, not simply giving responses to the economic, political and social demands but driving those thoughts and actions in the first run.

\section{References}

[1] Fitzsimons, P. (1999) 'Human capital theory and education', in M. Peters, P. Ghiraldelli, B. Zarnic \& A. Gibbons (Ed.) Encyclopaedia of Philosophy of Education. http://www.ffst.hr/ENCYCLOPAEDIA (18 December 2015) 
[2] Mouta, A., Paulino, A., Ferreira, J. and Couto, F. (2015) 'Pedagogy as a Techné: Meaningful ICT Integration in Formal Learning Scenarios', in Proceedings of the European Distance and E-Learning Network 2015 Annual Conference, pp. 64-72.

[3] UNESCO (2011) Transforming Education: The Power of ICT Policies, United Nations Educational, Scientific and Cultural Organization, France.

[4] Partnership for $21^{\text {st }}$ Century Skills (2009) 'P21 Framework Definitions', http://www.p21.org/storage/ documents/P21_Framework_Definitions.pdf (Access date: 3 September 2015).

[5] Anderson, J. (2010) ICT Transforming Education: A Regional Guide, UNESCO Bangkok, Thailand.

[6] Puentedura, R. (2013) 'SAMR: A Contextualized Introduction', http://www.hippasus.com/rrpweblog/ archives/2013/10/25/SAMRAContextualizedIntroduction.pdf (Access date: 2 September 2015).

[7] Mishra, P. and Koehler, M.J. (2006) 'Technological, Pedagogical Content Knowledge: A Framework for Teacher Knowledge', Teachers College Record, Columbia University, 108 (6), pp. 1017-1054.

[8] Paiva, J., Moreira, L., Teixeira, A., Mouta, A., Paulino, A., Ascensão, M. and Gonzaga, P. (2012) Information and Communication Technologies in Portuguese Primary Schools: a Study of the Educational, Social and Economic Impact. JP-ik, Universidade do Porto and Intel, Porto.

[9] Rancière, J. (2008) Le spectateur émancipé, La Fabriqueéditions, Paris.

[10] M.E. (2010) 'Ley de la Educación "Avelino Siñani Elizardo Pérez" Revolución en la Educación - N. ${ }^{\circ}$ 070'. Ministerio de Educación - Estado Plurinacional de Bolívia, p. 6.http://www.oei.es/quipu/bolivia/Leydla\%20.pdf

(Access date: 2 September 2015) 